\title{
First time identification of Pandoraea sputorum from a patient with cystic fibrosis in Argentina: a case report
}

Pablo F. Martina 1,5,6, Mónica Martínez², Guillermo Frada², Florencia Alvarez ${ }^{3}$, Lorena Leguizamón², Claudia Prieto ${ }^{5}$, Carolina Barrias ${ }^{2}$, Marisa Bettiol ${ }^{4}$, Antonio Lagares ${ }^{3}$, Alejandra Bosch $^{5}$, Julián Ferreras ${ }^{1,6^{*}}$ and Martha Von Specht ${ }^{2,6^{*}}$

\begin{abstract}
Background: Pandoraea species are considered emerging pathogens in the context of cystic fibrosis (CF) and are difficult to identify by conventional biochemical methods. These multidrug resistant bacteria remain poorly understood particularly in terms of natural resistance, mechanisms of acquired resistance and impact on the prognosis of the disease and the lung function. Among them, Pandoraea sputorum has been previously described in few cases of CF patients from Spain, Australia, France and United States, underlining the need of more clinical data for a better knowledge of its pathogenicity. This is the first report relating to $P$. sputorum in a CF patient in Argentina.
\end{abstract}

Case presentation: Pandoraea sputorum was identified in a nine-year-old cystic fibrosis patient from Argentina, after treatment failure during an exacerbation. The isolates were successfully identified by combining molecular techniques based on 165 rRNA sequencing and mass spectrometry (MS) methods, after reassessing previous misidentified isolates by conventional methods. After first isolation of $P$. sputorum, patient's clinical condition worsened but later improved after a change in the treatment. Although isolates showed susceptibility to trimethoprim-sulfamethoxazole and imipenem, in our case, the antibiotic treatment failed in the eradication of P. sputorum.

Conclusions: All combined data showed a chronic colonization with P. sputorum associated to a deterioration of lung function. We noted that the presence of $P$. sputorum can be underestimated in CF patients and MALDI-TOF MS appears to be a promising means of accurate identification of Pandoraea species.

Keywords: Pandoraea sputorum, Cystic fibrosis, First report, MALDI-TOF MS, Argentina

\section{Background}

In cystic fibrosis $(\mathrm{CF})$ patients, the main cause of morbidity and mortality is the decline in the pulmonary function subsequent to pathogenic colonization with non-fermenting Gram negative bacteria (NFGNB) [1]. Nevertheless, diverse bacterial species exhibit distinct degrees of pathogenicity and sensitivity patterns, requiring different clinical managements [2]. Regularly, a series of opportunistic pathogens colonizes the CF lung throughout life, often culminating in chronic infection

\footnotetext{
*Correspondence: juf2003@gmail.com; marthatovs@gmail.com ${ }^{1}$ Instituto de Biología Subtropical (IBS), CONICET-UNaM, Misiones, Argentina

${ }^{2}$ Hospital Pediátrico Dr F. Barreyro, Posadas, Misiones, Argentina

Full list of author information is available at the end of the article
}

with Pseudomonas aeruginosa and, less frequently, with Burkholderia cepacia complex (Bcc) organisms. Other opportunistic Gram-negative bacteria are also encountered. They include various Enterobacteriaceae, Stenotrophomonas maltophilia, Achromobacter xylosoxidans $[1,3]$ and species that are only occasionally associated with human infections apart from CF, such as Cupriavidus, Ralstonia, and Pandoraea species. Some of these species have been associated with poor outcomes in $\mathrm{CF}$, and the role that others may play in disease progression remains uncertain [2]. Bacteria from the Pandoraea genus (P. pulmonicula, P. pnomenusa, $P$. apista, $P$. norimbergensis and $P$. sputorum) are NFGNB that are being considered as emerging 
multi-drug resistant pathogens in the context of CF $[4,5]$. As they are still poorly known, particularly in terms of mechanisms of natural or acquired resistance and of their impact on lung function and the prognosis of the disease [5], more information is needed it to evaluate their pathogenic role. Conventional microbiology methods remain problematic for the accurate identification of Pandorea species and misidentification with bacteria of the genus Burkholderia or Ralstonia has been reported [6-8]. Moreover, isolates from CF patients with persistent pathogenic colonization often lose their characteristic phenotypes or growth conditions [9]. Therefore, descriptions of infections due to Pandoraea species in CF patients could be underestimated. The availability of MALDITOF MS in clinical microbiology diagnosis allows a quick and better identification of bacterial species, especially Pandoraea species $[5,8,10-12]$. In this study we report for the first time in Argentina, a lung colonization with Pandoraea sputorum, in a young CF patient who did not respond to antibacterial empirical treatment. Identification was possible after reassessing historical identification results obtained by conventional methods, using MALDI-TOF MS and sequencing of $16 \mathrm{~S}$ rRNA gene.

\section{Case presentation}

A 9-year-old boy who was diagnosed with $\mathrm{CF}$ at 29 months (heterozygous genotype F508del; sweat test positive: $\mathrm{Na} 74 \mathrm{mEq} / \mathrm{l}$ and $\mathrm{Cl}$ de $63 \mathrm{mEq} / \mathrm{l}$.), was transferred to our CF unit with a 5 years history of chronic bronchopulmonary colonization with Pseudomonas aeruginosa and Staphylococcus aureus. When the first microbiological cultures (always sputum samples) were performed in our laboratory in July 2014, P. sputorum was detected together with $S$. aureus, but was initially reported as S. maltophilia (Fig. 1). Previously, his pulmonary function test revealed a forced expiratory volume in $1 \mathrm{~s}\left(\mathrm{FEV}_{1}\right)$ of $83 \%$, and the preceding respiratory exacerbations were treated empirically with ceftazidime, amikacin and with aerosolized tobramycin. From the time of the first isolation of P. sputorum and during the next 2 months, his clinical condition worsened and exacerbations with increased cough and secretions were observed. The patient was treated with trimethoprimsulfamethoxazole $(4 / 20 \mathrm{mg} / \mathrm{kg} /$ day $)$ plus ciprofloxacin $(15 \mathrm{mg} / \mathrm{kg} /$ day $)$ and with aerosolized colistin $(2$ million units twice daily), however, his lung function declined $\left(\mathrm{FEV}_{1} 45 \%\right)$. In June 2015, the patient showed exacerbations with a dramatic deterioration of his pulmonary function $\left(\mathrm{FEV}_{1}\right.$ 27\%). A combined therapy for threeweeks of imipenem $(80 \mathrm{mg} / \mathrm{kg} /$ day $)$, amikacin $(40 \mathrm{mg} /$ $\mathrm{kg} /$ day), and inhaled colistin was initiated. Consequently, his clinical condition improved with a significant reduction in sputum volume and cough ( $\left.\mathrm{FEV}_{1} 40 \%\right)$. Five months later, his clinical condition was stable. In April 2016, a new respiratory sample was positive for $P$. sputorum, confirmed by MALDI-TOF MS, together with with $S$. aureus and $P$. aeruginosa.

Our laboratory records indicated that sputum cultures during patient's exacerbations and/or routine follow-up visits until July 2015, showed colonies of NFGNB without any clear phenotypic differences and $S$. aureus. Conventional identification of purple colonies recovered on B. cepacia complex selective agar plates (BCSA; Britania S.A, Argentina) was performed to some NFGNB

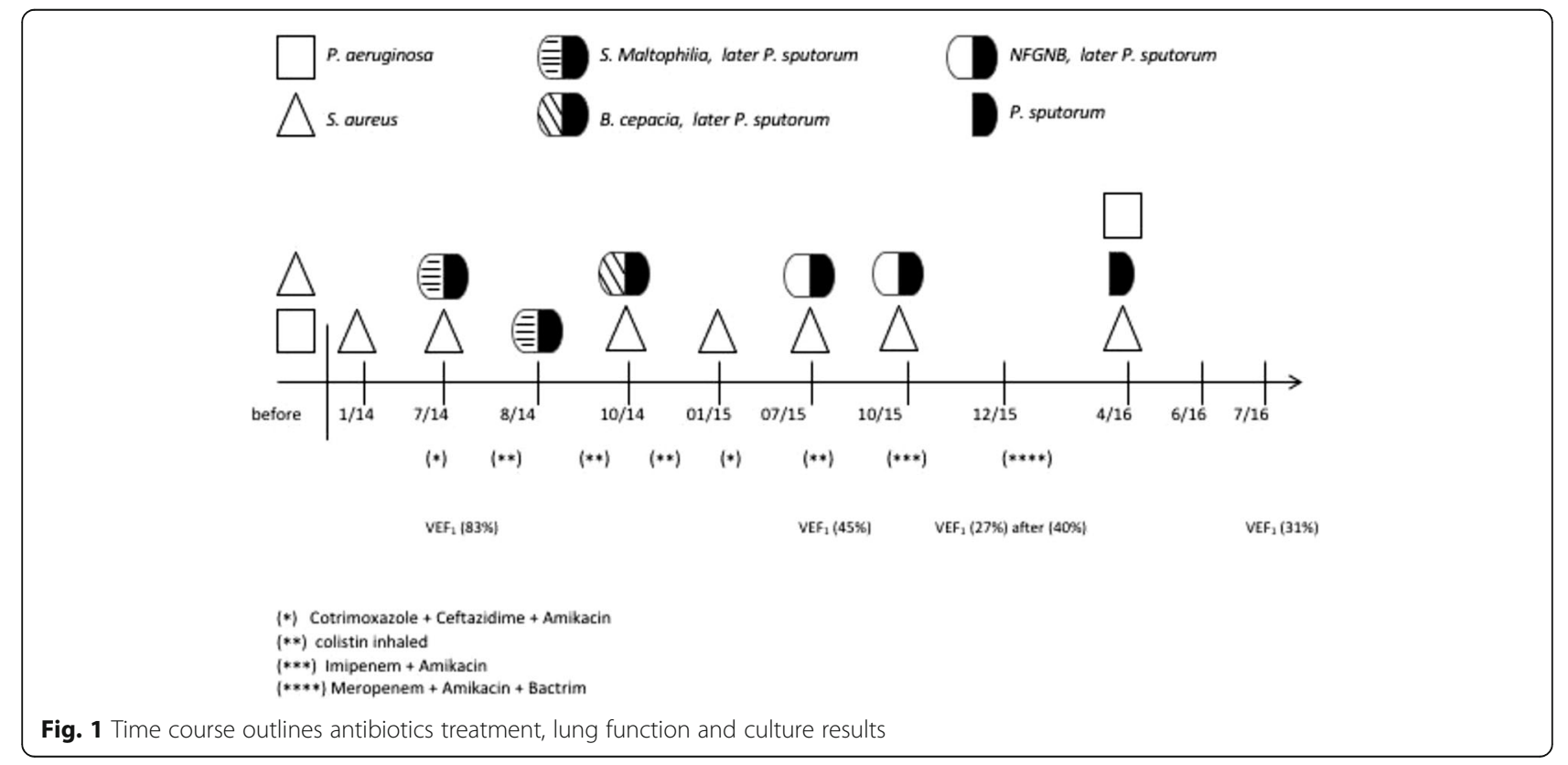


colonies. We used a combination of phenotypic tests [13] like oxidase activity, DNase, carbohydrate oxidation-fermentation, lysine and arginine decarboxylase, and motility tests. After these tests, isolates were reported as NFGNB $(\mathrm{n}=2), S$. maltophilia $(\mathrm{n}=2), B$. cepacia complex $(\mathrm{n}=1)$ and $S$. aureus $(\mathrm{n}=7)$. Later, one of the Gram-negative isolates was identified as Bordetella hinzii with a high identification confidence level (99\% probability) using VITEK2 automatic system (bioMérieux, France). Due to the inaccuracy of biochemical tests, we decided to reassess the identification of all NFGNB isolates $(\mathrm{n}=5)$ by Matrix Assisted Laser Desroption Ionisation-Time of flight (MALDI-TOF) mass spectrometry (MS), using an Ultraflex MALDI TOF/ TOF instrument and the MALDI Biotyper 3.1 software (Bruker Daltonics, Bremen, Germany). The five isolates were identified as Pandorea sputorum at species-level (score >2). Hierarchical cluster analysis based on MALDI-TOF MS spectra comparison clustered together, clinical isolates and the reference strain $P$. sputorum DSM $21091^{\mathrm{T}}$, while $P$. apista, P. pnomenusa, P. pulmonicola and $P$. norimbergensis were in a separate branch (Fig. 2). In addition, genetic relatedness was determined by fingerprinting analysis like BOX-PCR (Interspersed repetitive element) and ERIC-PCR (enterobacterial repetitive intergenic consensus) [14], revealing indistinguishable patterns among all our clinical isolates (data not shown). Finally, a subsequent full characterization through PCR and sequencing of 16S rRNA gene was performed using the corresponding universal primers (27 F and 1492R), previously published [15]. Sequence analysis of a 1400-bp fragment of the 16S rRNA gene of one of patient's isolate ( $P$. sputorum HP020) was performed. The corresponding sequence (GenBank accession KX258224) showed 99\% of similarity with $P$. sputorum DSM21091 ${ }^{\mathrm{T}}$ (GenBank accession CP010431), which confirmed the results obtained by MALDI-TOF MS analysis. The phylogenetic relationship among them was investigated by using MEGA 6.0 software (http://www.megasoftware.net) (Fig. 3).

Antibiotic susceptibility testing was performed using a disk diffusion method according to the recommendations of the committee of CLSI [16]. Susceptibility patterns were also identical for all isolates. In the absence of interpretive susceptibility criteria for strains of Pandoraea, results were interpreted using CLSI criteria for "other non-Enterobacteriaceae" isolates. The microorganism was resistant to amikacin, ceftazidime, cefepime, meropenem, gentamicin, aztreonam and colistin and susceptible to imipenem and trimethoprimsulfamethoxazole. Minimum inhibitory concentrations (MIC, mg/L) were estimated by Vitek2 Compac ${ }^{\circ}$ for amikacin $(\geq 64)$, ceftazidime $(\geq 64)$, cefepime $(\geq 64)$, ciprofloxacine $(\geq 4)$, colistin $(\geq 16)$, meropenem $(\geq 16)$, gentamicin $(\geq 64)$, piperacillin-tazobactam $(\geq 128)$, imipenem $(\leq 0,25)$ and trimethoprim-sulfamethoxazole (TMS, $\leq 1 /$ $20)$, which confirms the susceptibility profile.

\section{Discussion and Conclusions}

In the last decade, many emerging multidrug resistant pathogens have been described in CF patients including new species of the Burkholderia cepacia complex,

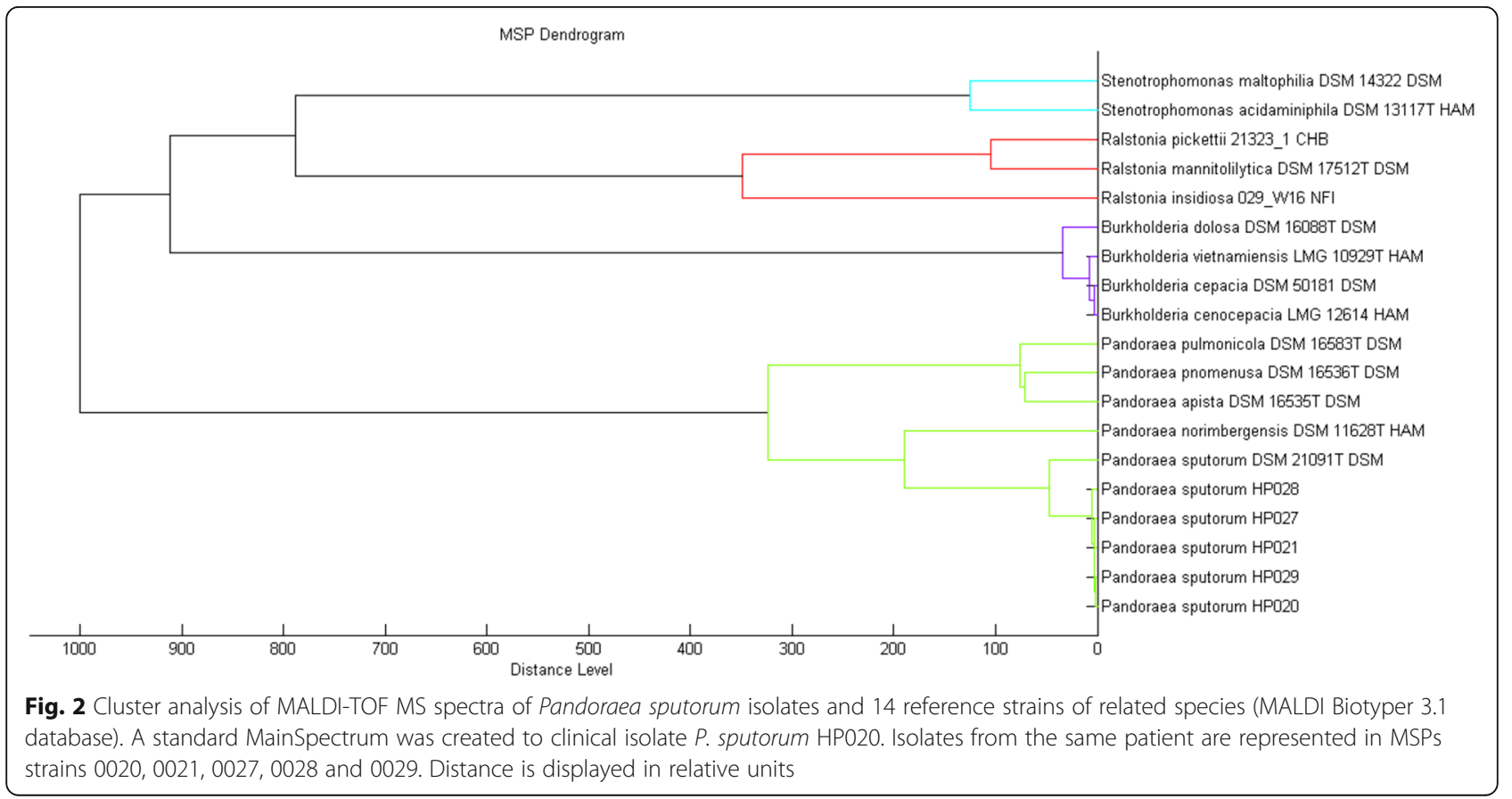




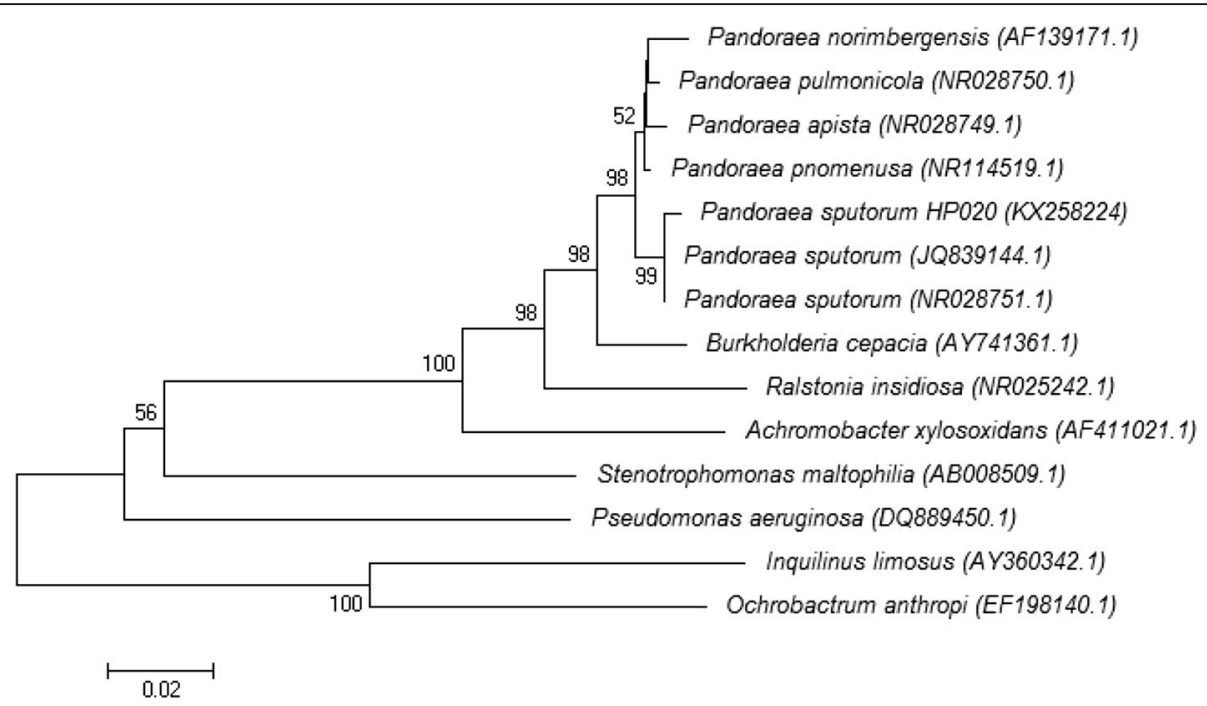

Fig. 3 Phylogenetic tree based on the 16S rDNA sequence of Pandoraea sputorum HP020 (KX258224) strain. The tree was constructed using a neighbor-joining method, and 1000 bootstrap by using MEGA6 software as previously described [22]. Values above the lines are bootstrap values expressed as percentages

Brevundimonas diminuta, Inquilinus limosus, Acetobacter indonesiensis, Achromobacter xylosoxidans, Ochrobactrum anthropi, and bacteria of the genus Pandoraea $[17,18]$. The pathogenicity of Pandoraea species remains controversial. These bacteria have been occasionally recovered from the lung transplant and/or respiratory tract of CF patients, as well as from blood cultures in non-CF patients and environmental samples $[2,4,8,19]$. In our review of the bibliography, we found few cases of CF patients chronically colonized with $P$. sputorum: one case from Australia [8], two cases from Spain [10, 11], and one case from France [5]. Interestingly, in our CF patient, $S$. aureus and $P$. aeruginosa were eventually isolated from respiratory tract cultures together with $P$. sputorum. This situation makes more difficult to know the real contribution of $P$. sputorum to the clinical condition of our patient. In this regard, intermittent or persistent colonization with Pandoraea species, that sometimes coincides with a deterioration in lung function, has been reported in addition to clinical evidence of invasive potential $[8,10,11,18]$. Furthermore, besides the inability of Pandoraea species to produce a biofilm in the respiratory tract [20], it remains still unclear the role of different virulence factors, mechanisms of pathogenicity, the possibility of transmission between patients, and their role in lung damage in $\mathrm{CF}$ patients. This situation emphasizes the importance of having more data about clinical cases. The Pandoraea genus is multidrug resistant and treatment may be problematic. In our case, $P$. sputorum was only susceptible to imipenem and TMS, with a low MIC for imipenem $(\leq 0,25 \mathrm{mg} / \mathrm{L})$, and although the treatment failed to eradicate the bacteria, the clinical condition improved. This pattern of being resistant to carbapenem and meropenem but sensitive to imipenem, appears to be unique to most Pandoraea genus [5, 21], and it can be a practical guideline in the earliest identification steps.

It is documented, when applying only conventional identification phenotypic methods, the microbiology laboratory commonly misidentifies this pathogen as Ralstonia, Stenotrophomonas or Burkholderia species [6-8]. It has been also noted the limitations of the sequences of $16 \mathrm{~S}$ rRNA and $\operatorname{gyr} B$ genes for differentiating the Pandoraea species $[8,22]$. The accuracy and usefulness of MALDI-TOF as a routine technique for rapid identification of bacterium was demostrated. Nevertheless, one factor limiting the use of MALDITOF MS is the scant reference data sets for microorganisms that are infrequently isolated from clinical specimens [10]. Due to these limitations, a polyphasic approach for an accurate identification is recommended. In our CF patient, all isolates were identified as $P$. sputorum, combining $16 \mathrm{~S}$ rRNA PCR and sequencing, and a MALDI-TOF MS proteomic platform. Lastly, to determine persistence over time of the same $P$. sputorum isolate, as generally occurs with $P$. aeruginosa and Bcc in CF patients, a molecular epidemiological analysis was performed $[2,23]$. BOXPCR and ERIC-PCR showed indistinguishable patterns among all isolates of $P$. sputorum (includeding last isolate collected in April 2016), indicating a possible chronic colonization, which is defined here as three positive cultures of the same strain isolated within a 6-month period.

In conclusion, we noted that the presence of $P$. sputorum can be underestimated in CF patients when using conventional biochemical identification methods. We also showed that $P$. sputorum may have a potential role in pulmonary function deterioration when chronically 
colonized CF patients, emphasizing the need to implement control policies to protect CF community. This is particularly relevant, as in our case, the treatment failed despite sensitivity to imipenem and trimethoprim-sulfamethoxazole. Finally, MALDI-TOF MS appears to be an excellent tool for an accurate identification of organisms of this genus.

\section{Abbreviations}

CF: Cystic fibrosis; CLSI: Clinical Laboratory Standards Institute; FEV1: Forced expiratory volume in one second; MALDI-TOF MS: Matrix-assisted laser desorption ionization-time of flight mass spectrometry; MIC: Minimum inhibitory concentration; NFGNB: Non-fermenting Gram-negative bacteria

\section{Acknowledgements}

The authors are grateful to the staff of the microbiology labs at Hospital Pediátrico Dr. F. Barreyro for their work in supporting treatment of the child in this case. We also thank to Analia Fortte for proofreading the manuscript

\section{Funding}

This work was partially funded by a grant from Fundación Roemmers (2014-2016).

\section{Availability of data and materials}

The datasets and materials during and/or analyzed during the current study available from the corresponding author on reasonable request.

\section{Authors' contributions}

PFM, JF, and MVS recognized the novelty of the case and drafted the manuscript. JF and MVS designed and coordinated the design and data acquisition. PFM, JF, and MVS analyzed and interpreted the results. JGF and $A C B$ were responsible for treating the patients. PFM, LL, FA, MM, MB, CP. $A B$ and $A L$ were responsible for the microbiology analysis. MM drafted the manuscript. All authors read and approved the manuscript.

\section{Author details}

PFM and JF are researchers at the National University of Misiones and the National Scientific and Technical Research Council (CONICET).

\section{Competing interests}

The authors declare that they have no competing interests.

\section{Consent for publication}

Written informed consent was obtained from the parents of the patient for publication in this case report. A copy of the written consent is available for review by the Editor of this journal.

\section{Ethics approval and consent to participate}

Ethical approval to report this case was not required.

\section{Author details}

'Instituto de Biología Subtropical (IBS), CONICET-UNaM, Misiones, Argentina. ${ }^{2}$ Hospital Pediátrico Dr F. Barreyro, Posadas, Misiones, Argentina. ${ }^{3}$ Instituto de Biotecnología y Biología Molecular (IBBM) - CONICET/UNLP, La Plata, Argentina. ${ }^{4}$ Hospital de Niños Sor María Ludovica, La Plata, Argentina. ${ }^{5}$ Centro de Investigación y Desarrollo en Fermentaciones Industriales (CINDEFI) - CONICET/UNLP, La Plata, Argentina. ${ }^{6}$ Facultad de Ciencias Exactas, Químicas y Naturales, Universidad Nacional de Misiones, Posadas, Argentina.

Received: 13 July 2016 Accepted: 21 January 2017

Published online: 07 February 2017

\section{References}

1. Hauser AR, Jain M, Bar-Meir M, McColley SA. Clinical significance of microbial infection and adaptation in cystic fibrosis. Clin Microbiol Rev. 2011;24:29-70

2. Lipuma JJ. The changing microbial epidemiology in cystic fibrosis. Clin Microbiol Rev. 2010;23:299-323.
3. Gibson RL, Burns JL, Ramsey BW. Pathophysiology and management of pulmonary infections in cystic fibrosis. Am J Respir Crit Care Med. 2003;168: 918-51

4. Coenye T, Liu L, Vandamme P, LiPuma JJ. Identification of Pandoraea species by 165 ribosomal DNA-based PCR assays. J Clin Microbiol. 2001;39: 4452-5.

5. Púges M, Debelleix S, Fayon M, Mégraud F, Lehours P. Persistent infection because of Pandoraea sputorum in a young cystic fibrosis patient resistant to antimicrobial treatment. Pediatr Infect Dis J. 2015:34:1135-7.

6. McMenamin JD, Zaccone TM, Coenye T, Vandamme P, LiPuma JJ. Misidentification of Burkholderia cepacia in US cystic fibrosis treatment centers: an analysis of 1,051 recent sputum isolates. Chest. 2000;117:1661-5.

7. Bosshard PP, Zbinden R, Abels S, Boddinghaus B, Altwegg M, Bottger EC 165 rRNA gene sequencing versus the API 20 NE system and the VITEK 2 ID-GNB card for identification of nonfermenting gram-negative bacteria in the clinical laboratory. J Clin Microbiol. 2006;44:1359-66.

8. Pimentel JD, MacLeod C. Misidentification of Pandoraea sputorum isolated from sputum of a patient with cystic fibrosis and review of pandoraed species infections in transplant patients. J Clin Microbiol. 2008;46:3165-8.

9. Wellinghausen N, Kothe J, Wirths B, Sigge A, Poppert S. Superiority of molecular techniques for identification of gram-negative, oxidase-positive rods, including morphologically nontypical Pseudomonas aeruginosa, from patients with cystic fibrosis. J Clin Microbiol. 2005;43:4070-5.

10. Fernández-Olmos A, Morosini M, Lamas A, García-Castillo M, García-García L, Cantón R, Máiz L. Clinical and microbiological features of a cystic fibrosis patient chronically colonized with Pandoraea sputorum identified by combining 165 rRNA sequencing and matrix-assisted laser desorption ionization-time of flight mass spectrometry. J Clin Microbiol. 2011;50: 1096-8.

11. Martínez-Lamas L, Rabade-Castedo C, Romero-Domínguez M, BarbeitoCastiñeiras G, Palacios-Bartolomé A. Pérez del molino Bernal M. Colonización por Pandoraea sputorum en un paciente con fibrosis quística. Arch Bronconeumol. 2011:47:571-4.

12. Miñán A, Bosch A, Lasch P, Stämmler M, Serra DO, Degrossi J, Gatti B, Vay C, D’aquino M, Yantorno O, Naumann D. Rapid identification of Burkholderia cepacia complex species including strains of the novel taxon $\mathrm{K}$, recovered from cystic fibrosis patients by intact cell MALDI-ToF mass spectrometry. Analyst. 2009;134:1138-48.

13. Henry DA, Mahenthiralingam E, Vandamme P, Coenye T. Phenotypic methods for determining genomovar status of the Burkholderia cepacia complex. J Clin Microbiol. 2001;39:1073-8.

14. Versalovic J, Schneider M, de Bruijn FJ, Lupski JR. Genomic fingerprinting of bacteria using repetitive sequence-based polymerase chain reaction. Methods Mol Cell Biol. 1994:5:25-40.

15. Lane DJ. 16S/23S rRNA sequencing. In: Stackebrandt E, Goodfellow M, editors. Nucleic acid techniques in bacterial systematics. . New York: Wiley; 1991. p. $115-76$

16. Clinical Laboratory Standards Institute. Performance standards for antimicrobial susceptibility testing; 25th informational supplement. CLSI document M100-S25. Wayne: CLSI; 2015.

17. Davies JC, Rubin BK. Emerging and unusual gram-negative infections in cystic fibrosis. Semin Respir Crit Care Med. 2007;28:312-21.

18. Kokcha S, Bittar F, Reynaud-Gaubert M, Mely M, Gomez C, Gaubert J, Thomas P, Rolain JM. Pandoraea pulmonicola chronic colonization in a cystic fibrosis patient. France New Microbe New Infect. 2013;1:27-9.

19. Costello A, Herbert G, Fabunmi L, Schaffer K, Kavanagh KA, Caraher EM, Callaghan M, McClean S. Virulence of an emerging respiratory pathogen, genus Pandoraea, in vivo and its interactions with lung epithelial cells. J Med Microbiol. 2011:60:289-99.

20. Caraher E, Collins J, Herbert G, Murphy P, Gallagher C, Crowe M, Callaghan $\mathrm{M}, \mathrm{McClean} \mathrm{S}$. Evaluation of in vitro virulence characteristics of the genus Pandoraea in lung epithelial cells. J Med Microbiol. 2008;57:15-20.

21. Schneider I, Queenan AM, Bauernfeind A. Novel carbapenem-hydrolyzing oxacillinase OXA-62 from Pandoraea pnomenusa. Antimicrob Agents Chemother. 2006;50:1330-5.

22. Coenye T, LiPuma JJ. Use of the gyrB gene for the identification of Pandoraea species. FEMS Microbiol Lett. 2002;208:15-9.

23. Martina $\mathrm{P}$, Bettiol M, Vescina $\mathrm{C}$, Montanaro $\mathrm{P}$, Mannino $\mathrm{MC}$, Prieto $\mathrm{Cl}$, Vay C, Naumann D, Schmitt J, Yantorno O, Lagares A, Bosch A. Genetic diversity of Burkholderia contaminans isolates from cystic fibrosis patients in Argentina. J Clin Microbiol. 2013;51:339-44. 